\title{
Lost in Transnationalism: Unraveling the Conceptualisation of Families and Personal Life Through a Transnational Gaze
}

\author{
by Sue Heath, Derek McGhee and Paulina Trevena \\ University of Manchester; University of Southampton; University of Southampton
}

\author{
Sociological Research Online, 16 (4) 12 \\ <http://www. socresonline.org.uk/16/4/12.htm/> \\ $10.5153 /$ sro. 2534
}

Received: 13 Jun 2011 Accepted: 3 Nov 2011 Published: 30 Nov 2011

\begin{abstract}
This paper compares and contrasts some of the conceptual language used to engage with the realm of family and personal life within the parallel fields of transnational family studies (TFS) and British family studies (BFS). Key concepts which are now widely referenced within BFS - such as 'family practices', 'family display', 'families of choice' and 'connectedness' - have not been widely drawn upon within TFS. Instead, TFS scholars are developing alternative concepts such as 'ways of being' versus 'ways of belonging' and 'frontiering and relativising', often to capture very similar ideas to those current within BFS. This paper critically explores some of the concepts currently being used within transnational family studies, highlighting points of similarity and difference with the BFS tradition, and considers what these parallel literatures might learn from each other. The paper is illustrated by examples drawn from ESRCfunded research on the experiences of post-accession Polish migrants living in the UK.
\end{abstract}

\section{Keywords: Transnationalism, Polish Migration, Family Practices, Family Display, Connectedness}

\section{Introduction}

1.1 This paper arises from our own recent experiences of border crossing: in this case, our crossing of the sub-disciplinary borders between family studies and migration studies as part of ESRC-funded research on the (re)migration decisions of post-2004 Polish migrants living in the UK. [1] More specifically, we explore the contrasting conceptual language used to engage with the realm of the personal within the parallel fields of British family studies (BFS) and transnational family studies (TFS). As is evident from other contributions to this special issue, BFS has been invigorated in recent years by a questioning of the language of 'the family' and has sought to engage with alternative conceptualisations of the personal, including through engagement with the concepts of intimacy, relationality, personal life and connectedness, and through making explicit links to often marginalised fields of study, such as the sociology of the body, emotions and sexuality (Smart 2007). In parallel, there has been a recent call for a sexual and emotional turn in migration studies (Mai and King, 2009), as well as a call to focus on the importance of non-blood ties in practices of 'family making' (Bryceson and Vuorela 2002). Our paper does not rehearse in any great detail the conceptual debates which are current within BFS, as these are covered elsewhere in this collection. ${ }^{[2]}$ Rather, we seek to explore some of the key concepts used within transnational family studies and to consider what each tradition might learn from the other. We use examples from our own research by way of illustration, but the focus of the paper is conceptual rather than empirical, not least because Polish migration to the UK is arguably a special case within the field of transnationalism, a point explained more fully below.

1.2 'Transnationalism' has emerged in recent years as a widely used but often contested concept within migration studies, placing emphasis on the extent to which individuals, groups and organisations are presumed to operate across national borders and are reliant upon ongoing commitments which straddle those borders. Portes et al. (1999: 221) distinguish between 'transnationalism from above', actions by powerful organisations such as governments and multinationals; and 'transnationalism from below', actions generating from the grassroots. The ways in which migrants organise their family lives across borders constitute an example of 'transnationalism from below', with transnational families defined as: 
families that live some or most of the time separated from each other, yet hold together and create something that can be seen as a feeling of collective welfare and unity, namely 'familyhood', even across national borders (Bryceson and Vuorela 2002:3).

1.3 The field of transnational family studies pays particular attention to the everyday personal and domestic lives of migrants and their families, and highlights the degree to which migrants are actively engaged in kinship practices which transcend geographical distance and national borders. Such concerns have, until recently, remained fairly marginal within European migration research, in contrast with a more long standing engagement amongst researchers working in the Americas and the Asian-Pacific region (Kofman 2004; Bailey and Boyle 2004).

1.4 Key topics in this more established body of TFS research have included: family unification rights (more specifically, their frequent absence), marriage-related migration, family formation and post-migration reconfigurations of family structures (eg Constable 2004; Palriwala and Uberoi 2008); the impact of family migration on parent-child relationships, for example how families cope with the devaluing of parents' cultural competencies and the acquisition by migrant children of responsibilities more usually associated with parents) (Portes and Rumbaut 2001; Levitt and Water 2002); explorations of the long-distance parenting practices of migrant mothers (eg Parreñas 2005); the intergenerational 'caring deficit' that can result from migration (eg Baldasser et al. 2007); and the broader structural inequalities, including those relating to gender, class and processes of racialisation, which govern family migration practices (Glick Schiller et al. 1992; Pessar and Mahler 2003). In exploring these themes, the experiences of non-migrant family members are deemed to be equally as important as those of their border-crossing relatives, and the ways in which both groups negotiate family responsibilities and caregiving across time and space, as well as across different stages of the life course, are invariably central to these accounts (see, for example, Bryceson and Vourela 2002; Baldassar et al. 2007; Goulbourne et al. 2010).

1.5 The emergence of TFS has, then, acted as a corrective to what Vertovec (2004) regards as an overemphasis in much migration research on the social institutions of transnationalism at the expense of the accounts of social actors:

To balance the picture, we also need to observe transnationalism as it occurs within, and has impact upon, the daily lives of individuals... While actor-centered (sic) approaches carry the danger of overlooking larger structural conditions, they have the advantage of emphasizing motivations, meanings and the place of people as their own agents in processes of change (Vertovec 2004: 973).

1.6 A more recent intervention has called for a sexual and emotional turn in migration studies, paralleling the foregrounding of these aspects of intimacy and personal life within British family studies in recent years (eg Smart 2007; Weeks et al. 2001). Mai and King (2009) have noted that love for partners, children, parents, broader kin or friends is often a key factor in individuals' (re)migration decisions, whilst there is also growing evidence of the importance of sexualities in influencing the movements of many migrants and asylum seekers. They have accordingly called for 'the intersectionality of love, sex and emotion in framing mobility behaviour' (ibid: 297) to be placed at the centre of analysis within migration studies, rather than at the margins. They regard this as a rebalancing of mainstream migration research paradigms which tend to focus on either the working lives of migrants and their socio-structural position (a focus associated with economic and sociological perspectives) or their socio-cultural positionality and identity (concerns associated with anthropological and cultural studies perspectives):

It is as if migrants are not allowed to love, express their sexualities, have emotions, be intimate... we need to recognise that migrations (sic) are rarely exclusively motivated by economic or political considerations, and that the full relevance of the decision to migrate and to continue living and working abroad can only be understood by bringing into analytical equation the affective, the sexual and emotional dimensions (Mai and King 2009: 297).

1.7 Themes such as these have become increasingly central to debates within British family studies (BFS), as evidenced by this special issue. Yet ideas and concepts which are becoming increasingly commonplace within the study of relationships and personal life in the UK are rarely referenced in the TFS literature, whilst concepts relating to family practices which are gaining currency within TFS are largely unknown within BFS, despite the two fields of study sharing many similar concerns. This partly reflects the anthropological orientation of much TFS research, in contrast to the largely sociological orientation of BFS, but also the extent to which these two fields tend to operate with fairly tight boundaries around their subject matter, including their conceptual literatures.

1.8 As researchers, we each took up quite different positions of expertise in relation to these two fields of study at the outset of our project, and have engaged in our own processes of border crossing as we have considered the relative usefulness of the concepts and ideas offered by the two perspectives. In this sense, these different concepts of family and personal life can be viewed as 'boundary objects', objects which, according to McSherry (2001: 69, cited in Strathern 2003), 'hold[...] different meanings in different social worlds, yet [are] imbued with enough shared meaning to facilitate [their] translation across those worlds.' Strathern (2003: 46) develops this idea further, noting that boundary objects, rather than marking the limits of understanding, are instead 'entities at the borders of discourses, that is, entities which set up borders in themselves, but do not presuppose that a border is also an enclosure.' It is in this spirit of border crossing that, after a brief introduction to our own research, we spend the rest of the paper critically engaging with two sets of ideas from TFS which we have found particularly helpful and/or challenging: Levitt and Glick Schiller's (2004) distinction between migrants' ways of being and ways of belonging as a way of understanding the significance of varied transnational family practices, and Bryceson and Vuorela's 
(2002) concepts of frontiering and relativising as a way of understanding the significance of practices specifically concerned with transnational family-making. We conclude the paper with some reflections on the usefulness of these concepts to our own research as well as to British family studies more generally.

\section{Polish transnationalism: a special case?}

2.1 Our own research - 'International labour mobility and its impact on family and household formation among Polish migrants living in England and Scotland' - has explored the impact of family and householdrelated factors on the (re)migration decisions of 'new' Polish migrants living in the United Kingdom (that is, those who have arrived since European Union accession in 2004). Fieldwork was conducted in four case study locations (Glasgow, Southampton, rural Dorset and Highland Perthshire) and consisted of in-depth interviews with 20 migrants in each location, all of whom had been resident in the UK for at least 12 months. The interviews explored a range of themes, including participants' migration biographies and their post-migration experiences of employment, housing and household formation; the nature of their family and friendship networks both in the UK and in Poland; their means of maintaining contact with non-migrants friends and family members; and their plans for the future with respect to family and household formation and possible remigration.

2.2 Polish migration to the UK arguably constitutes a 'special case' in relation to the field of TFS. The Accession Treaty of 2003, which led to the incorporation into the EU in 2004 of the so-called 'A8' countries of central and Eastern Europe, was subject to transitional arrangements which placed restrictions on the otherwise guaranteed free movement of A8 workers. Yet the UK, alongside Ireland and Sweden, permitted free movement from the outset, and Polish migrants to the UK are able to access similar social rights to UK citizens. For these reasons, post-accession Polish migrants have far greater agency than migrants in many other contexts, and have greater protection against the sorts of broader structural inequalities which govern migration practices in many non-EU contexts.

2.3 Even so, Moskal (2011:32) has argued that 'the transformation of Europe into a single market represents a significant conceptual challenge for conventional accounts of family migration' (emphasis added), as EU social rights still privilege work-related mobility over care-related mobility. Moreover, many Polish migrants experience discrimination, racism, and difficulties arising from language barriers. Neither are they immune from concerns relating to care-giving at a distance or to the challenges presented by family unification, whether in the UK, in Poland or elsewhere. Nonetheless, UK-based Polish migrants and their families are not generally affected by the more extreme conditions of migration experienced in many other contexts: they are not subject to stringent migration control, they are much less likely to have undocumented migrant status, and have relatively few legal restrictions placed on family unification. We are aware, then, that the Polish case is limited in terms of its atypicality. Accordingly, we use our own research merely by way of illustration, rather than to make wider claims about transnational families per se.

\section{'Ways of being' and 'ways of belonging'}

3.1 The development of transnational theory has reflected a concern that the field of migration studies has too often assumed a discontinuity between migrants' home countries and their countries of destination. With its long standing concern with integration, identity and assimilation, mainstream research within migration studies has often tended to place greater emphasis on 'rupture, uprooting and loss of homeland', with 'an 'either/or' approach to home and host allegiances' (Baldassar et al. 2007:11). In contrast, transnationalism seeks to emphasise the degree to which migrants may actively maintain ties to multiple locations and develop 'dual' or 'hybrid' identities (ibid).

3.2 This is not claimed as a new phenomenon, but it has been widely argued that the recent developments of new communication technologies and cheaper and faster modes of travel have accelerated the degree to which this occurs, making it much easier for migrants to retain active links to their home country (Urry 2000; Wilding 2006; Metykova 2010). The participants in our own research, for example, are very well versed in the use of social networking media, including specialist Polish social networking sites, are adept users of Skype and other cut price telephone services, often subscribe to Polish satellite television channels, and are frequent users of budget airlines operating between the UK and Poland. Several participants regularly used cheap flights specifically to visit doctors and dentists back in Poland, whilst one claimed to have had a friend who would occasionally fly back to Poland for the weekend to visit their favourite cinema.

3.3 Transnational family researchers, then, look for continuity of experience, as these examples suggest, whereas dominant theoretical models and frameworks within migration studies more generally tend to point researchers towards seeing disjuncture. There is an interesting parallel here with Smart's advocacy of a 'connectedness thesis' within British family studies, in contrast to the dominance within much contemporary theorising of personal life of accounts which privilege individualization:

With [individualisation], one is directed towards gathering information and evidence about fragmentation, differentiation, separation and autonomy. And it also becomes a mindset or inferential framework through which information is interpreted... Connectedness as a mindset encourages enquiry about all kinds of sociality and seeks to understand how association remains both possible and desirable as well as how it takes many different shapes at different times (Smart 2007:189).

3.4 TFS researchers are similarly inclined to explore sociality and association, rather than fragmentation and independence, and to focus on these phenomena as they are played out across borders. Nonetheless, a criticism which is frequently leveled at transnational family studies relates to the danger of overinterpreting the significance of migrants' everyday practices with regard to family and home, and of looking 
for transnational connectedness where there is none - or none intended. Transnational theory more generally is often accused of overstating the degree to which migrants are consciously and deliberately engaged in transnational practices of various kinds, as if almost everything migrants do is, by definition, 'transnational' (White 2011:8). Castles and Miller (2009) note, for example, that few migrants are able to live their lives with a constant self-awareness of the degree to which their lives are being played out across borders. An important question to ask, then, is whether the implied distinction between 'ordinary' family practices and transnational family practices is a useful one; and if so, what constitutes a specifically transnational family practice as opposed to a non-transnational (intra-national?) family practice.

3.5 Food practices constitute an interesting context within which to explore this question, as they are often closely associated with ideas regarding home, family, homeland and nationalism. Rabikowska (2010), for example, has focused specifically on the ritualisation of food, home and national identity among postaccession Polish migrants living in London. We use the example of Dorota ${ }^{[3]}$, a 32 year old woman who lives with her partner and her sister. Dorota's decisions surrounding food purchasing and preparation highlight the difficulty of identifying what, if anything, might be distinctively 'transnational' about certain family practices. Since 2004, Polish food shops have sprung up in large numbers across the UK. Dorota, in common with many of our research participants, regularly buys Polish bread and cheese from local Polish shops, explaining that this is because 'English' bread and cheese is 'just not edible'. She then qualifies this statement by adding that she and her sister are not actually particularly fussy about their own food habits, but that her partner, Stanislaw, is:

But Stanislaw is just not up to eating English food. He cannot eat English bread. He has to have Polish bread and he is fussy and I don't want any conflicts because of that, so I just go to the Polish shop and that's it.

3.6 Dorota explains further that 'I make an effort to cook according to Polish cuisine' and describes her efforts to find decent cuts of meat. Once again, she stresses that the need to find certain types of meat and to cook it in particular ways is attributable to Stanislaw's tastes, not hers:

I'm not that bothered about meat myself, I prefer fish and barley, but there's a man in the house, so... if he doesn't have his potatoes and meat and salad, then it's not a dinner for him.

3.7 The purchasing and cooking of Polish food is, then, variously explained by Dorota in terms of the inferiority of indigenous products, her partner's fussiness, gendered expectations of what constitutes a 'proper' meal, and her wish to avoid domestic conflict. These are considerations which are closely related to family practices of care and emotional labour which are by no means unique to migrant families, although the transnational context may give them an added potency. Nonetheless, it is difficult to see how Dorota's food practices, described in these terms, might constitute a distinctively 'transnational' family practice.

3.8 Levitt and Glick Schiller's (2004: 1006) 'transnational social field' approach, which seeks to distinguish between 'the existence of transnational social networks' on the one hand and 'the consciousness of being embedded in them' on the other, is potentially very useful in teasing out distinctions between 'everyday' and transnational practices. They argue that this distinction is 'critical to understanding the experience of living simultaneously within and beyond the boundaries of a nation-state and to developing methodologies for empirically studying such experiences' (ibid). Levitt and Glick Schiller distinguish between migrants' ways of being within a social field and their ways of belonging to that field. The former refers to 'the actual social relations and practices that individuals engage in rather than the identities associated with their actions', whilst the latter refers to 'practices that signal or enact an identity which demonstrates a conscious connection to a particular group... ways of belonging combine action and an awareness of the kinds of identity that action signifies' (2004:1010 emphases added). Many of the other families in our research, for example, purchase, prepare and eat Polish food primarily because it is what they are used to eating. Marek, a 31 year old who migrated to the UK in 2005, summed this up succinctly: 'we've been raised to like certain things and you won't find equivalents here.' The food choices of Polish migrants in this sense constitute a 'transnational way of being', and would only constitute a 'transnational way of belonging' if and when they ate Polish food as a self-conscious assertion of Polish family identity, for example when celebrating traditional feast days or other holidays.

3.9 Levitt and Glick Schiller assert, then, that there has to be a claiming of an action for it to be regarded as an expression of belonging:

If individuals engage in social relations and practices that cross borders as a regular feature of everyday life, then they exhibit a transnational way of being. When people explicitly recognise this and highlight the transnational elements of who they are, then they are also expressing a transnational way of belonging. Clearly, these two experiences do not always go hand in hand (ibid: 1011).

3.10 In practice, it may be difficult to draw this distinction with any great confidence. The example of eating Polish food on special occasions is a case in point, and many of our participants spoke, for instance, of observing the practice of a special meal with family members and/or close friends on Christmas Eve, often including the preparation of a traditional carp dish. Yet how is it possible to determine whether these traditions are primarily observed because they are a deeply rooted and habitual way of being (an everyday 'family practice' (Morgan 1996)) or because they are a deliberate expression of belonging (presumably, a specifically transnational family practice)? It can be both, of course, and Levitt and Glick Schiller's approach encourages researchers to delve into the intended meanings which lie behind actions. 
3.11 Interestingly, this approach is echoed in a distinction which has recently emerged within British family studies between family practices and family display. The former is a concept which seeks to underline that 'family' is less about reified structures and more about everyday process (Morgan 1996; 2011). Hence the idea of family as a verb - 'doing family':

A whole set of what appears to be trivial or even meaningless activities is given meaning through its being grouped together under one single label, that of family. The focus on doing, on activities, moves us away from ideas of the family as relatively static structures or sets of positions or statuses. (Morgan 2011: 6).

3.12 We noted earlier that a potential difficulty arises in distinguishing between specifically transnational family practices as opposed to non-transnational family practices. We might equally ask what is distinctive about family practices as opposed to other forms of everyday practice. Cheal (2002:12, quoted in Morgan 2011) has argued that 'family practices consist of all the ordinary, everyday actions that people do, insofar as they are intended to have some effect on another family member': in other words, family practices are relational and 'are carried out with reference to some other family member' (Morgan 2011: 10). In this sense, sharing food with other family members is a straightforward example of an everyday family practice, and it is through such practices that 'family' is constantly constituted and (re)configured. It seems to us that Levitt and Glick Schiller (2004) extend this idea to transnational contexts through emphasising the importance of 'ways of being' to reinforcing a sense of migrant family identity and solidarity at the level of the everyday.

3.13 More recently, the concept of family practices has been contrasted with that of family display:

Families need to be 'displayed' as well as 'done'... In order to be effective as family practices, these actions need to be understood by others as carrying meaning associated with 'family'... Display is the process by which individuals, and groups of individuals, convey to each other and to relevant audiences that certain of these actions do constitute 'doing family things' and thereby confirms that these relationships are 'family' relationships' (Finch 2007: 66-67 - emphases in original).

3.14 Finch argues that display is essential within a social context where family relationships are increasingly diverse and fluid. She emphasises that the concept and the practices of 'doing' family are not, then, the same as the concept and the practices of 'displaying' family. The former, she argues, embraces a very broad range of family practices, many of which are so deeply embedded within certain types of relationships that there is no need to consciously 'display' family. Rather, the need to actively 'display family' becomes more pressing the further one's family relationships move away from more conventional notions of family.

3.15 The family lives of many migrants might similarly require more deliberate and overt display which, Finch argues, is achieved primarily through social interaction, at times 'supported and reinforced' through tools such as narratives and visual artefacts such as photographs and personal possessions. (On this last point, most participants actually reported bringing few personal effects with them to the UK, and the home spaces of those whom we interviewed in their own residences were invariably fairly spartan, largely devoid of family photographs or other mementos.) For Finch, the critical factor in successful family display is that observers as well as individual actors must recognise an action as constituting a display of family for it to be validated as such. Yet this is potentially problematic, inasmuch as some sets of relationships - families headed by same-sex couples, for example (Almack 2008; Gabb 2011) - may be deemed by observers to be so outside observers' preconceived notions of family life that they may refuse to acknowledge certain actions as constituting displays of family, regardless of actors' intentions. Similarly, practices of care and support associated with transnational families - 'spatially dispersed and seemingly capable of unending social mutation' (Bryceson and Vuorela 2002:3) - may seem to some observers to be so at odds with preconceived notions of family life that they too might be misrecognised and discounted as legitimate family displays. As Heaphy (2011:37) has argued, 'alternative or critical displays of family are weak displays within our culture', with potential audiences for those displays 'unwilling to receive, interpret and validate them as desirable or viable alternatives to family.'

3.16 Gabb (2011) also draws attention to what goes undisplayed in family life, noting that not all aspects of family are, or need be, accompanied by recognisable displays to make them meaningful. Migrant families may have good reason not to engage in overt displays of family, if it brings unwelcome attention in its wake. The strength of Levitt and Glick Schiller's emphasis on 'ways of belonging' is that the intentions of actors are ultimately what count, rather than the interpretations and/or recognition of outsiders alone. Relying on the interpretations of outsiders alone also creates a risk that researchers 'see' transnational ways of belonging in everyday practices which are perhaps better categorised as ways of being, or indeed fail to see them at all.

\section{Families as imagined communities: 'frontiering' and 'relativising'}

4.1 Bryceson and Vuorela (2002) offer additional tools for conceptualising the family practices and familial claims of migrants through a focus on aspects of agency and everyday practice. Whilst interested in those who remain behind when family members migrate, the hybrid identities that may thus ensue, and the pull that the 'homeland' might exert on migrants, they are also anxious to explore the networks which are formed by migrants in their host countries in the absence of regular physical contact with non-migrant kin. They argue that families are essentially 'imagined communities', rather than 'natural, given facts':

One may be born into a family and a nation, but the sense of membership can be a matter of choice and negotiation... even if we think that we do not choose our relatives, we in fact do, 
4.2 They propose, then, a fluid and dynamic conceptualisation of family, one which can be compared to the concept of 'families of choice' advanced by writers such as Weeks et al (2001), and which also has much in common with Smart's (2007) call for a more inclusive focus on broader forms of intimacy and connectedness. Transnational families are, then,

...not simply blood ties nor are they fixed entities. They are highly relative. (Bryceson and Vuorela 2002: 19)

4.3 In attempting to capture the many and varied processes by which migrants engage in specific practices of 'transnational family making', Bryceson and Vuorela propose two umbrella concepts: frontiering and relativising. They use the term frontiering to denote the ways and means transnational family members use to create familial space and network ties in terrain where affinal connections are relatively sparse' (2002:11), whilst relativising refers to 'the variety of ways individuals establish, maintain or curtail relational ties with specific family members' and to 'modes of materialising the family as an imagined community with shared feelings and mutual obligations' (ibid: 14). Frontiering is more concerned with practices which engage migrants in an interface between their own and the host society culture, whilst relativising includes a more outward looking dimension through focusing on the ways in which a sense of 'being related' is created 'by active pursuit or passive negligence' of both kin and non-kin, including those 'left behind'. In practice, though, there seems to be considerable overlap between these two concepts: both are concerned with everyday practices relating to forms of relationality, and both stress the importance of engaging with non-kin as well as kin in order to create a sense of belonging and community.

4.4 Amongst our own research sample, frontiering practices have invariably involved creating connections with other migrants, most commonly other Poles, rather than with British nationals. Contacts with the indigenous population have often tended to be fairly tenuous, with poor English rather than a lack of willingness to engage often acting as a barrier to close friendship. Making connections with other Poles, though, is by no means straightforward, with many participants expressing considerable ambivalence towards, if not open dislike of, other migrants. As for relativising practices, we have already noted the widespread use of new technologies to retain and foster links with friends and family members in Poland and elsewhere, including compatriots living in the UK. According to Bryceson and Vuorela, transnational families 'have to construct their notion of a family and its emotional and economic utility more deliberately, rather than taking it for granted through continuous day to day interaction' (2002: 15). Certainly, unwillingness to engage with new technologies, or a selective engagement with them, makes it likely that relationships will lapse or be neglected, whereas migrants who make regular use of Skype, email and other technologies may, paradoxically, retain closer ties with their non-migrant kin than those living in relatively close geographical proximity.

4.5 It was also not at all unusual for sample members to have migrated to the UK with several family members, with implications for migrants' capacity to sustain or neglect their relationships with non-migrant friends and relatives. Moreover, many migrants had been 'brought over' by relatives already living in the UK, including in some cases by relatives who had arrived in the UK (sometimes illegally) prior to 2004, whereas others had subsequently 'brought over' relatives themselves. The nature of chain migration amongst new Polish migrants, whereby inhabitants from the same sending communities have tended to migrate en masse to the same UK destinations, also meant that even those who migrated alone were often known to fellow migrants from their home towns and villages.

4.6 This sense of potential ongoing surveillance was significant, as many participants argued that one of their reasons for migrating was to establish their independence from certain of their close kin relationships (see too Torunczyk-Ruiz 2008; Ryan et al 2009; White 2010). For younger Poles in particular, one of the attractions of migration was the ability to live independently of their families of origin, an unusual arrangement in Poland, where most young people remain within the parental home - often with a partner and children - until their late twenties and early thirties (Mandic, 2008; Roberts 2009). For young single migrants, the opportunity to live with friends and/or with their partners outside marriage and the parental home, and to form 'imagined families' free from traditional expectations and constraints, was often extremely important. Whilst this group were often relatively relaxed about the distances (both literal and metaphorical) that existed between them and their non-migrant family members, those with children tended to feel the pull of family and spoke of missing the support of parents and other relatives. It was important to them that their children would know who their blood relatives were and not regard them as distant strangers. These examples support Bryceson and Vuorela's contention that 'relativising' entails a continual revision of one's family identity at different stages of the life course, yet also underpin the importance of traditional definitions of family for many migrants concerned with their broader sense of belonging and identity.

\section{Conclusion}

5.1 This paper has highlighted the development of transnational family studies as a distinct sub-field of migration research. It has noted that the conceptual language of TFS is quite distinct from that of British family studies, despite many areas of overlap. There are, of course, many differences in emphases, and we have noted some of the particular concerns of TFS. We have explored the usefulness of Levitt and Glick Schiller's work on ways of being and ways of belonging, and Bryceson and Vuorela's work on frontiering and relativising, and have illustrated these different concepts through examples drawn from our own research.

5.2 A key question for us has been whether these concepts bring something new to our own research, or whether we could have explored similar themes through using the conceptual tools which have emerged 
within BFS recent years. One way of answering this question is to revisit our querying of the implied distinction between 'ordinary' family practices on the one hand and transnational family practices on the other. Our own early frustrations with this distinction are captured well by Goulbourne et al. (2010), who note the relative dearth of theoretical discussion of the concept of transnational families within existing TFS literature:

It is assumed that the concept is a straightforward description of families whose members live in different countries but manage to keep in touch with each other. Of course, to a large extent this is indeed the case. But left in this way the concept is of little analytical use because it remains too large, too porous, and therefore too vague; the phenomena that we perhaps intuitively sense to be new remain elusive or slippery (Goulbourne et al. 2010:4)

5.3 They similarly argue that the definition of transnational families offered by Bryceson and Vuorela (2002:3) - 'families that live some or most of the time separated from each other, yet hold together and create something that can be seen as a feeling of collective welfare and unity, namely 'familyhood', even across national borders' - is 'all too vague a definition'. This is a view with which we have some sympathy. TFS (at least in part) sets out to foreground the significance of 'doing family' at a distance, and in so doing highlights practices that might be unique to such circumstances, yet it is not unusual for non-migrant families to be very widely geographically dispersed and, in the absence of day to day interaction, obliged to engage in very deliberate practices of family-making.

5.4 Because of this potential overlap, the concept of family practices used widely within BFS seems to us to provide a useful starting point for considering the importance of the everyday in constructing the boundaries of migrant families and can be developed further to incorporate family practices which have a very specific transnational dimension. The mundane 'ordinariness' of many aspects of migrants' family lives, which has often been downplayed, is thus underlined, whilst at the same time acknowledging that certain aspects, however 'ordinary' to those involved, are nonetheless important in forging and reinforcing ongoing transnational connections. Levitt and Glick-Schiller's language of 'ways of being' and 'ways of belonging' provides a very useful further distinction, one which has encouraged us to think more carefully about the intentions which lie behind family practices, including the extent to which family practices may be very deliberate assertions of family identity on the part of migrants, and which may (possibly only) take on particular significance in transnational contexts.

5.5 The concept of 'family display', which may be gaining ground in British family studies (Seymour and Dermott, 2011), does not seem to us to be quite so analytically useful in this sense, not least because in its original formulation (Finch, 2007) it accords greater weight to the interpretations of observers than it does to the intentions of actors. Nonetheless, Finch's argument that the need for deliberate display becomes more pressing the further one's family relationships move away from conventional notions of family could usefully be applied to many transnational families, notwithstanding our concerns that by no means all displays achieve equal recognition by observers.

5.6 The unique contribution of the language of frontiering and relativising is more difficult to access, as the distinctions between the two terms are not straightforward. Nonetheless, Bryceson and Vuerola's concepts highlight the fluidity of migrants' networks and the importance of thinking beyond conventional typologies of family in both understanding the types of connections which are made by migrants and the ways in which those connections are nurtured. As we have argued, these ideas have much in common with the emphasis within BFS on 'families of choice' (Weeks et al 2001) and on the inclusive notion of relationality and connectivity associated with the work of Smart (2007). Yet regardless of the fluidity of definitions of family and relationality conjured up by these accounts, the lives of many migrants remain highly constrained by legal definitions of what counts as 'family'. As Kofman notes, 'when we speak of family migration in the European Union context, we mean the nuclear family as defined by the state; migrants cannot determine for themselves the persons who constitute their family... The 'family of choice' is still some way off' (Kofman 2004: 245).

5.7 Goulbourne et al. (2010) also argue that ideas of family fluidity are often alien to the rather more traditional family typologies prevalent in typical sending nations. They imply, then, that concepts developed within particular national contexts are not always easily transferable into transnational contexts.

Nonetheless, a frequent outcome of migration is (at the very least) a reconfiguration of the nuclear family: parents migrating to live in the homes of adult children, for example; a parent living alone in the host country whilst the rest of the family remain in the country of origin; siblings living together in the receiving country whilst their parents remain in their country of origin (Ryan et al. 2009). These reconfigurations are central to the processes of frontiering and relativising.

5.8 In concluding, we revisit our suggestion that these different concepts of family and personal life have the potential to act as 'boundary objects', 'entities at the borders of discourses, that is, entities which set up borders in themselves, but do not presuppose that a border is also an enclosure' (Strathern 2003:46). The different concepts explored in this paper have, to date, tended to exist within sub-disciplinary enclosures, yet they are all ultimately concerned with the same classic sociological concerns regarding practices of solidarity and conflict within the realm of 'the personal'. We have demonstrated the benefits of using concepts from both fields of study in our own research, in order to further interrogate what might be distinctively 'transnational' about the ways in which Polish migrants 'do family', and as such we hope that this paper might extend further the ongoing dialogue between the two fields.

\section{Acknowledgements}

We would like to extend our gratitude to the anonymous reviewers of this paper, whose comments were 


\section{Notes}

${ }^{1}$ The project, 'International labour mobility and its impact on family and household formation among Polish migrants living in England and Scotland', is funded by the Economic and Social Research Council as part of the work programme of the ESRC Centre for Population Change, a joint initiative between the University of Southampton and a consortium of Scottish Universities in partnership with the Office for National Statistics and the General Registrar Office in Scotland (ESRC grant reference number RES-625-28-0001).

${ }^{2}$ See in particular the contributions to this volume by Gabb and Silva, Morgan, and Gillies.

${ }^{3}$ All names used are pseudonyms.

\section{References}

ALMACK, K (2008) 'Display work: lesbian parent couples and their families of origin negotiating new kin relationships', Sociology, 42 (6): 1183-99. [doi:://dx.doi.org/10.1177/0038038508096940]

BAILEY, A \& Boyle, P (2004) 'Untying and retying family migration in the New Europe', Journal of Ethnic and Migration Studies, 30 (2): 229-41. [doi:://dx.doi.org/10.1080/1369183042000200678]

BALDASSER, L., Baldock, C.V., \& Wilding, R. (2007) Families Caring Across Borders: Migration, Ageing and Transnational Caregiving. Basingstoke: Palgrave.

BRYCESON, D. \& Vuorela, U. (2002) The Transnational Family: New European Frontiers and Global Networks. Oxford: Berg.

CASTLES, S. \& Miller, M. (2009) The Age of Migration: International Population Movement in the Modern World: Fourth Edition. Basingstoke: PalgraveMacmillan.

CONSTABLE, N. (2004) Cross-Border Marriages: Gender and Mobility in Transnational Asia. Philadelphia: University of Pennsylvania Press.

FINCH, J. (2007) 'Displaying families', Sociology, 41 (1): 65-81.

[doi:://dx.doi.org/10.1177/0038038507072284]

GABB, J. (2011) 'Troubling displays: the affect of gender, sexuality and class', in J.Seymour and E. Dermott (eds) Displaying Families: A New Concept for the Sociology of Family Life. Basingstoke: Palgrave Macmillan.

GLICK SCHILLER, N., Basch, L \& Blanc-Szanton, C (eds) (1992) Towards a Transnational Perspective on Migration: Race, class, ethnicity and nationalism reconsidered. New York: New York Academy of Sciences.

GOULBOURNE, H., Reynolds, T., Solomos, J., and Zontini, E. (2010) Transnational Families : Ethnicities, Identities and Social Capital. London : Routledge.

HEAPHY, B., (2011) 'Critical relational displays', in J.Seymour and E. Dermott (eds) Displaying Families: A New Concept for the Sociology of Family Life. Basingstoke: Palgrave Macmillan.

KOFMAN, E (2004) 'Family-related migration: a critial review of European Studies', Journal of Ethnic and Migration Studies, 30 (2): 243-62. [doi:://dx.doi.org/10.1080/1369183042000200687]

LEVITT, P \& Glick Schiller, N. (2004) 'Conceptualising simultaneity: a transnational social field perspective on society', International Migration Review, 38 (3): 1001-39.

LEVITT, P \& Waters, M. (2002) The Changing Face of Home; The Transational Lives of the Second Generation. New York: Russell Sage Foundation.

MAI, N. \& King, R. (2009) 'Love, sexuality and migration: mapping the issue(s)', Mobilities, 4(3): 295-307. [doi:://dx.doi.org/10.1080/17450100903195318]

MANDIC, S. (2008) 'Home-leaving and its structural determinants in Western and Eastern Europe: an exploratory study', Housing Studies, 23 (4): 615-37. [doi:://dx.doi.org/10.1080/02673030802112754]

MCSHERRY, C (2001) Who Owns Academic Work? Battling for Control of Intellectual Property. Cambridge: Harvard University Press.

METYKOVA, M (2010) 'Only a mouse click away from home: transnational practices of Eastern European migrants in the United Kingdom', Social Identities: Journal for the Study of Race, Nation and Culture, 16 (3): 325-38.

MORGAN, D. (1996) Family Connections. Cambridge: Polity Press. 
MORGAN, D. (2011) Rethinking Family Practices. Basingstoke: Palgrave Macmillan. [doi:://dx.doi.org/10.1057/9780230304680]

MOSKAL, M (2011) 'Transnationalism and the role of family and children in intra-European labour migration', European Societies, 13 (1): 29-50. [doi:://dx.doi.org/10.1080/14616696.2010.497225]

PALRIWALA, R \& Uberoi, P. (eds) (2008) Marriage, Migration and Gender. New Delhi: Sage.

PARRENAS, R (2005) Children of Global Migration: Transnational Families and Gendered Woes. Stanford: Stanford University Press.

PESSAR, P. \& Mahler, S (2003) 'Transnational migration: bringing gender in', International Migration Review, 37 (3): 812-46. [doi:://dx.doi.org/10.1111/j.1747-7379.2003.tb00159.x]

PORTES, A., Guarnizo, L and Landoldt, P. (1999) 'The study of transnationalism: pitfalls and promise of an emergent research field', Ethnic and Racial Studies, 22 (2): 242-82.

[doi:://dx.doi.org/10.1080/014198799329468]

PORTES, A and Rumbaut, R (eds) (2001) Ethnicities: Children of Immigrants in America. Berkeley: University of California Press.

RABIKOWSKA, M (2010) 'The ritualisation of food, home and national identity among Polish migrants in London' Social Identities: Journal for the Study of Race, Nation and Culture, 16 (3): 377-98.

ROBERTS, K. (2009) Youth in Transition: Eastern Europe and the West. Basingstoke: Palgrave Macmillan.

RYAN, L., Sales, R., Tilki, M. and Siara, B. (2009) 'Family strategies and transnational migration: recent Polish migrants in London', Journal of Ethnic and Migration Studies 35 (1): 61-77.

[doi:://dx.doi.org/10.1080/13691830802489176]

SEYMOUR, J and Dermott, E. (2011) Displaying Families: A New Concept for the Sociology of Family Life. Basingstoke: Palgrave Macmillan.

SMART, C. (2007) Personal Life. Cambridge: Polity.

STRATHERN, M (2003) Commons and Borderlands. Wantage: Sean Kingston Publishing.

TORUNCZYK-RUIZ, S. (2008) 'Being together or apart? Social networksandnotionsof belonging among recent Polish migrants in the Netherlands', CMR Working Papers, No. 40/98. Warsaw: Centre of Migration Research.

URRY, J. (2000) Sociology beyond Societies: Mobilities for the Twenty-First Century. London: Routledge.

VERTOVEC, S. (2004) 'Migrant transnationalism and mode of transformation', International Migration Review, 38 (3): 970-1001. [doi:://dx.doi.org/10.1111/j.1747-7379.2004.tb00226.x]

WEEKS, J., Heaphy, B. and Donovan, C. (2001) Same-Sex Intimacies: Families of Choice and Other Life Experiments. London: Routledge. [doi:://dx.doi.org/10.4324/9780203167168]

WHITE, A. (2010) 'Young people and migration from contemporary Poland', Journal of Youth Studies, 13 (5): 565-80. [doi:://dx.doi.org/10.1080/13676261.2010.487520]

WHITE, A. (2011) Polish Families and Migration Since EU Accession. Bristol: Policy Press.

WILDING, R. (2006) '"Virtual" intimacies? Families communicating across transnational contexts', Global Networks: A Journal of Transnational Affairs, 6 (2): 125-42. 